\title{
INEFFICIENCY IN SPECTRUM AUCTIONS - EMPIRICAL EVIDENCE
}

\author{
Agnieszka KUŚ \\ Pope John Paul II State School of Higher Education in Biała Podlaska, Faculty of Economic Sciences; \\ a.kus@dydaktyka.pswbp.pl, ORCID: 0000-0002-6258-6823
}

\begin{abstract}
Purpose: The spectrum is scarce recourses, so it is very important to allocate it in a way to maximize the economic and social returns to the countries` economies. Economists agree that the best way to allocate rare resources are auctions. Despite their good properties, in some environments, they can create inefficiency. We describe some potential sources of inefficiency in spectrum auctions and some negative effects of inefficient spectrum allocation. We also discuss how the government through appropriate spectrum policy and auction designing can promote efficient spectrum allocation.
\end{abstract}

Design/methodology/approach: The paper is based on the literature on the spectrum auction and public documents published by national spectrum authorities. Theoretical discussions are supported by case studies of real world spectrum auctions. Much attention has been paid to the case of the Polish 4G auction.

Findings: Extremely high reserve prices or rigorous approach to promoting entry could lead to price distortions, misallocation or even unsold spectrum which harm both competition and consumers. The case of the Polish $4 \mathrm{G}$ auction confirms that gaps in the detailed auction rules may lead to significant delays in frequency allocation and increase the risk of an ineffective auction outcome.

Practical implications: In the light of our findings, it is important that the rules of the auction in the $3.6 \mathrm{GHz}$ band currently planned in Poland should allow the regulator to control the pace of the auction and take into account the risk of inefficient outcome associated with passive bids. Originality/value: The discussions made in this paper could help policy makers in Poland and other countries in spectrum auction designing.

Keywords: spectrum auction, inefficiency, Polish 4G auction, spectrum policy, auction design.

Category of the paper: Case study.

\section{Introduction}

Auctions are now a common way of spectrum assigning in both developed and emerging countries. Before auctions, licenses were most often allocated through comparative selection 
procedures (called beauty contests) or lotteries (which were popular especially in the US) ${ }^{1}$. One of the reasons for resigning from beauty contests was that they ran too slowly and raised concerns about objectivity. In turns, lotteries encouraged the participation of bidders without the prime objective to acquire and use spectrum but rather to resell them at much higher prices, which harmed the public interest. Auctions save time needed for comparative hearings and are more transparent than administrative procedures (McMillan, 1994). The auction rules are relatively simple and clearly defined. Moreover, they must be accepted by each participant before the auction, which reduces the risk of challenging the final result.

Auctions leave spectrum valuation to operators who, unlike spectrum regulators, have more information about the market situation and can better estimate the real value of a license. They express this information in their bids, which increases the chances of obtaining a license by the most competitive operators. By introducing market mechanisms into the assignment process, auctions are generally more efficient than administrative procedures. A well designed spectrum auction "can maximise societal benefits of a scarce resource and ensure that economic rent is obtained by the public rather than shareholders" (OECD, 2000, p. 4).

Despite many advantages, auctions also have some weaknesses. The success of the auction largely depends on how it was designed. In particular, the auction rules have been adapted to the specific market situation in which they will be applied. There is evidence that auctions, in some circumstances, may lead to distorted outcomes resulting in inefficiency (GSMA, 2014; Earle, and Sosa, 2013).

The aim of this paper is to present potential sources and negative effects of inefficiency at spectrum auctions and discuss how the government (spectrum regulators) through appropriate spectrum policy and auction designing can promote efficient spectrum allocation. We start by determining what efficiency means in relation to spectrum assignment. In section 3 we discuss some sources and possible negative effects of inefficiency in spectrum auctions. Theoretical discussions are supported by the examples of actual spectrum auctions. Potential inefficiency during the Polish 4G auction was discussed in section 4. Section 5 concludes.

\section{The efficiency of spectrum auctions}

At the early stage of using spectrum auctions, one of the basic criteria for evaluating the efficiency was revenue, and the successful auctions were considered those that ended with high prices. An example may be the series of European UMTS auctions from the years 2000-2001.

\footnotetext{
1 In Europe, administrative procedures based on the comparative assessment of applications against a predetermined set of criteria were the primary form of licensing until 2000. In 2000-2001, a series of European auctions for third-generation mobile licenses took place which contributed to the spread of spectrum auctions in Europe (See: Cave, Webb, 2013).
} 
Then the auction in the UK obtained high prices of $4.31 \$ / \mathrm{MHz} /$ pop was considered a success, while the auction in the Netherlands where the prices were several times lower - a failure. The fact that the auction in the Netherlands allowed for the distribution of $355 \mathrm{MHz}$ of spectrum, much more than in any other European UMTS auction was often ignored. The approach of ranking the auction based on the revenue alone often contradicts the original reason why administrative procedures and lotteries were dropped in favour of competitive bidding. This reason was that competitive bidding probably allocated licenses to companies that could use them in the most productive way ignored (Hazlett et al., 2012).

The fast technological development and a significant increase in the demand for mobile services made spectrum a scarce resource and gained its value. The efficiency of using this rare resource began to gain more and more importance, often putting the auction revenues in the background. Nowadays, economists often point out that focusing on revenue maximization is short-sighted and does not benefit the economy in the long run. Instead of maximizing revenues, the main goal of the government should be efficiency and competition in the market, which in the long run will bring the government more benefits, lead to better and cheaper services (Cramton, 2013; Cramton et al., 2011). Recently governments also paying more and more attention to the effectiveness of spectrum allocation. The efficiency of using the spectrum was one of the common goals during the European $5 \mathrm{G}$ auctions so far. For instance, in UK Ofcom in the "Statement Award of the 2.3 and $3.4 \mathrm{GHz}$ spectrum bands" defines its purpose as follows: „In light of our duties, our objective is to design the auction in a way that enables the allocation of the spectrum to those bidders most likely to put it to the most efficient use and deliver the highest possible value to society. In so doing, we consider that it should be designed in a manner that promotes competition. We consider that this should fulfil our duty to secure the optimal use of the spectrum and enable us to achieve our wider policy objective that everyone in the UK can enjoy fast and reliable mobile broadband services" (Ofcom, 2017, p. 15).

There are many approaches to the concept of efficiency in microeconomic. One of the basic ones is connected with efficient allocation which means mechanisms ensuring that the goods sold go to the bidders who value the item the most (Maskin, 2003). This approach is in line with the seller's revenue maximization concept but is not always appropriate for spectrum auctions. Spectrum, as a scarce resource and of great importance for the economy, should be distributed in a way that ensures the greatest social welfare. Assigning a license to the operator who values it the most does not always agree with this purpose. An example would be the monopolist that probably values the licenses the most, because in his valuation it takes into account future profits related to the exclusion of rivals, thus maintaining its monopolistic position in the market. However, it would be better for consumer and generally for social welfare if the new entrant obtains a license as this would improve competition, which in the future is likely to result in lower retail prices and more innovative services (Cramton et al., 2011; van Damme, 2002). Thus, the efficiency in spectrum assignment should be considered as an assigning spectrum to those participants, which could generate the greatest economic value for society 
(Zehle, 2019). This will be of direct public benefit because it will ensure that consumers and businesses can all realize the greatest available value from using the frequencies.

As Hazlett and Munoz pointed: "to maximize consumer welfare, spectrum allocation should avoid being distracted by side issues like government license revenues" (Hazlett et al., 2012, p. 95). Focusing on revenue is therefore the wrong approach. It can lead to many distortions of auction results that are inconsistent with social welfare. In the next section we will discuss some sources and possible effects of inefficiency in spectrum auctions, based on examples of real spectrum auctions.

\section{The inefficient outcomes on spectrum auctions - evidence from actual auctions}

While market mechanisms are generally the most efficient way to distribute spectrum, they may not, under certain circumstances, lead to an outcome that maximizes social welfare such as incomplete allocation or inefficient spectrum use (Rosston, Steinberg, 1997). The main source of ineffectiveness in spectrum auctions are problems related to the market structure, especially asymmetry between participants and the related distortions of competition. Unequal opportunities between participants harm both the competition at the auction and the competition on the post-auction market. The common asymmetry in telecommunication markets is the asymmetry between incumbent and smaller operators. The incumbents have a stronger market position: apart from the customer base, they also have some spectrum resources and infrastructure, which lowers the costs of network deployment and implementation of new services and increases the chance of winning a license. In addition, the incumbent has a greater incentive to win a license because. in the event of failure, he may lose not only the chance for new customers but also the existing ones.

Regulators have a number of instruments to level the playing field and promote competition. The evidence confirms that these instruments should be used with caution because, if used improperly, they may be a source of inefficiency and led to the failure of the auction. In the following, we will discuss examples of auctions where inappropriate policy choices led to some auction distortion.

\subsection{Spectrum aggregation limits}

Excessive spectrum concentration in the hands of one or a small group of operators and the existing barriers of entry may have negative effects on the market. It weakens the competitive pressure from market participants, creates a field for tacit coordination and increases the risk of higher detail prices (Cave, Webb, 2013). Spectrum aggregation limits are a common tool used by authorities around the world to prevent these unfavourable occurrences. These restrictions 
may apply to the amount of spectrum that the operator can get at the auction or may refer to the operator's total resources in a given band, including those he had before the auction ${ }^{2}$. Another form could be to reserve a license for new entrants or existing small operators.

Although aggregation limits in many cases were effective (for example, during the UMTS auction in the UK they allowed a new player (Three) to enter the market, which improved competition in the English mobile services market and speeded the implementation of new technologies in the UK), there is evidence that, if used incorrectly, an aggressive policy to promote new market entry may lead to resource misallocation and many other distortions of results or its inefficient use (Earle, and Sosa, 2013).

An example could be the Dutch $2.6 \mathrm{GHz}$ auction in 2010. The auction offered $190 \mathrm{MHz}$ spectrum divided into 13 paired 2x5MHz blocks (FDD), 10 unpaired 5MHz blocks (TDD) and additionally two $5 \mathrm{MHz}$ guard blocks. In order to promote the new entry, the regulator implemented strict spectrum limits that applied to the general resources of operators in the $900 \mathrm{MHz}, 1800 \mathrm{MHz}$ and $2.1 \mathrm{GHz}$ bands, which significantly limited the possibilities of incumbent operators. As a result of applied restrictions, new entrants were able to bid up to $50 \mathrm{MHz}$ TDD and 2x20 MHz FDD, while one of the incumbents (T Mobile) was limited to one $2 \times 5 \mathrm{MHz}$ block (Marsden et al., 2010). Due to the very restrictive spectrum caps imposed on the incumbent operators, there was insufficient demand for unpaired blocks, which resulted in $55 \mathrm{MHz}$ remaining unsold generating economic losses related to the delay in accessing to improved service.

Another example is the Canadian $600 \mathrm{MHz}$ band auction in 2019. There were $70 \mathrm{MHz}$ band ( 7 blocks of paired spectrum $2 \times 5 \mathrm{MHz}$ ) available in 16 service areas. During this auction, the regulator did not introduce restrictions concerning the amount of spectrum that each participant can purchase at the auction, but in order to encourage competition, 3 blocks in each service area have been reserved for "facilities-based providers" who are defined as "not national incumbent service providers, and that are actively providing commercial telecommunications services to the general public in the license area of interest" (ISED, 2018). While the 3 existing incumbent operators (Bell, Telus, and Rogers) were excluded from bidding on reserved blocks, other participants were allowed to bid on all blocks (both, set aside and not set aside) what advantaged them significantly. Such an unfavourable for incumbent set-asides design led to 8 blocks in six regions remaining unsold despite the fact that there was excess demand from open bidders. Set-asides in conjunction with combinatorial clock auction (CCA) format resulted in some other non-competitive and unfavourable for consumers outcomes of the Canadian auction. The first is excessively concentrated ownership: in many regions, two delivers have acquired all available spectrum. The second problem was a huge difference in the prices paid by incumbents and "facilities-based providers" (Ostrowsky, 2019).

\footnotetext{
${ }^{2}$ This type of restriction was commonly used during European auctions of digital dividend and often applied to general resources of operators in sub-1-GHz band (Cave, Webb, 2013).
} 
Set-aside constraints were also a problem during the Canadian Advanced Wireless Spectrum (AWS) auction in the $2 \mathrm{GHz}$ band in 2008 . With the aim of introducing the fourth national wireless provider, almost half of the $105 \mathrm{MHz}$ spectrum available at the auction was reserved for new entrants and smaller regional providers. In this case (as in 2019), the auction rules strongly favoured new non-incumbent as they were eligible to bid on all blocks, while incumbent operators were allowed to submit bids only for not set-asides blocks. All available spectrum was sold during this auction, however other problems arose. The set-aside spectrum was purchased by 5 participants: 3 new entrants (PublicMobile, Wind, Mobilicity) and two regional players (Videotron and EastLink), but only the latter two participants successfully implemented services using the acquired frequencies. After the 5-year lock-up period, PublicMobile sold the licenses to the incumbent Telus, Mobilicity filed for bankruptcy and Wind became insolvent after "its Europeanbased financial backer, VimpelCom, wrote off its \$768-million investment in the start-up" (Masse, and Beaudry, 2014, p. 30). The attempt to introduce a national provider remained unsuccessful (did not lead to a permanent entry into the market) and was costly for the society. The set-aside blocks were sold at a discount of about $30 \%$ compared with the blocks open to bidding by all operators. According to CIBC World Markets, this amounted to a \$617-million subsidy for new entrants (Masse, and Beaudry, 2014). Despite such a high subsidy, the set-aside spectrum was not used effectively.

A similar situation took place during the UMTS auction in Germany in 2000. The auction included $120 \mathrm{MHz}$ of spectrum divided into twelve 2 x $5 \mathrm{MHz}$ lots, but each bidder could buy only from 2 to 3 blocks. The available spectrum went to 4 incumbent operators and two new participants (MobilCom and Group 3G) who withdrew from the market shortly after the auction and did not use the acquired spectrum. The 3G group filed for bankruptcy in 2002, while MobilCom returned its license to the German regulator in 2003 (Earle, and Sosa, 2013). The remaining spectrum was only sold in 2010 during the $4 \mathrm{G}$ auction causing 10 years delays in allocating $3 \mathrm{G}$ bands.

Economists do not agree on the reasons for the failure of the German auction. According to Early and Sosa, the policy limiting the ability to bid for individual players contributed to the loss to consumers of access to improved mobile services (Earle, and Sosa, 2013). Cramton, on the other hand, argues that the result of the German auction cannot be regarded as a confirmation of the failure of spectrum limits, explaining that the spectrum limits at this auction were not binding and incumbents were not constrained by the limits (Cramton, 2013b).

In our opinion, perhaps spectrum limits were not the only reason for the inefficient spectrum allocation in Germany, but the fact that the participants acquired spectrum below the limits does not proof that set-asides had no effect (were not binding) and didn't matter to the auction failure. The incumbents initially reported their demand for 3 blocks, which indicates that they were interested in 3 or even more number of blocks, so spectrum cups could limit their actual requirements. The fact that they finally got only 2 blocks could result from this, that the prices reached a level higher than their value of the third block. In such a situation rational players 
(as probably were incumbents) resigned from bidding in order to avoid the winner's curse. Moreover, a policy promoting a new entry encouraged entities that otherwise might not have decided to participate, sparked their enthusiasm which probably led to overbid their values of licenses. All of this indirectly contributed to the fact that, similarly to Canada, the spectrum went to operators who did not have sufficient funds to use them effectively.

\subsection{Reserve prices}

The reserve price is the minimum price at which the regulatory authority agrees to sell licenses. It is a measure that allows the government to achieve a certain level of revenue from selling licenses. In the case of competitive auctions, the starting price will probably be irrelevant to the final prices. Nevertheless, in a situation where, for example, due to onerous coverage obligations, the government expects limited competition in the auction, reserve price may be a way to provide a country with an economic rent that reflects its value.

Setting reserve prices is not an easy decision as each choice comes with some risk. Low minimum prices increase the risk of collusion to acquire spectrum at a low price. Moreover, in the case of weak competition, it exposes the government to low revenues and the need to sell the license at a price below its social value, which harms consumers. On the other hand, too high reserve price may discourage new entrants, which reduces the competition and increases the chances of unsold lots (Mochon, and Saez, 2017).

Too high minimum prices are often the cause of unsuccessful auctions, where all or part of the spectrum remains unsold, generating losses for the public. An example can be the multiband auction in India in 2016. This was multiband auction included $700 \mathrm{MHz}, 850 \mathrm{Mhz}$, $900 \mathrm{MHz}, 1800 \mathrm{MHz}, 2100 \mathrm{Mhz}, 2300 \mathrm{MHz}$ and $2500 \mathrm{MHz}$ ranges. Due to high reserve prices, $60 \%$ of the offered spectrum remained unsold and the revenue from the auction amounted to only $11.6 \%$ of the total sum of minimum prices. ${ }^{3}$ Among the bands that did not find buyers, there was all an extremely important and valuable for operators $700 \mathrm{MHz}$ band, which is the most suitable for ensuring coverage in rural areas. The fact that this band was lying fallow for several years has damaged the Indian telecommunications market and deprived consumers of the possibility of access to better quality services. According to analysts from Coleago Consulting, this result could have been avoided and the government was informed about it before the auction. Obtaining significant revenue was, however, the goal of the Indian government, which, despite warnings about excessive asking prices and wrong methodology of setting them, decided not to change the established auction rules (Zehle, 2019).

High reserve prices also resulted in unsold licenses at the 2013 Australia 4G auction. The asking prices at this auction were extremely high, especially for the $700 \mathrm{MHz}$ band, for which prices were set at $\$ 1.36 / \mathrm{MHz} /$ pop. This was 186 percent of the average price paid at

\footnotetext{
${ }^{3}$ According to Coleago Consulting the reserve prices for all spectrum available in the auction were over twice the annual industry revenue (Zehle, 2019).
} 
other auctions for the spectrum from the digital dividend. Extremely high minimum prices led to the fact that $30 \mathrm{MHz}$ of the $90 \mathrm{MHz}$ offered in the $700 \mathrm{MHz}$ band remained unsold. According to Coleago Consulting, it generated losses due to unsold licenses of several billion USD. Another damage to the market was distorted competition resulting from the fact that one of the operators (Vodafone) did not obtain a license in this band until 2017, when this band was again put up for sale (Australian spectrum auction failure, 2013).

\subsection{Coverage obligations}

Formulas Coverage obligations are one of the instruments used by the regulatory authority to achieve goals regarding the scope and development of the network. They could be considered as some indirect form of financing network development (Webb, 2010). When defining obligations, policymakers are faced with a trade-off between coverage improvement and revenues. This is due to the fact that potential licensees include their offers costs related to the fulfilment of obligations, so they will be willing to pay less for a license on which certain obligations are imposed. The difference between what an operator is willing to pay for a license without obligation and a license with obligation can therefore be seen as a loss of revenue for the government or the amount that the government contributes to supporting the implementation of broadband coverage (GSMA, and Frontier Economic, 2015).

Generally, coverage obligations can have many positive effects on the market. They support the efficient use of spectrum and encourage competition in the development of network infrastructure, which in turn may translate into a competition between operators and lower prices of mobile services (Eylert, 2005). However, if they are too restrictive, going beyond consumer demand, they can harm the market and consumers. The example could be UMTS auctions in Sweden and Norway. In both countries, the regulator has implemented very stringent rollout obligations ( $80 \%$ of population in Norway and $99.98 \%$ in Sweden). The operators asked for a change them, arguing this with the difficult market situation. However, the regulator decided not to relax originally established obligations, which resulted in the withdrawal of foreign participants (newcomers) from the auctions, and reduced competition during the auction (Eylert, 2005). ${ }^{4}$

The extensive obligations imposed on all auction winners can also lead to costly and inefficient duplication of infrastructure, especially in economically unprofitable rural areas. To avoid this type of inefficiency, regulators could use a number of preventive instruments:

- the Italian regulator, during the $20185 \mathrm{G}$ auction for the $700 \mathrm{MHz}$ band, in addition to the individual coverage obligations for each winner, also specified more restrictive but collective obligations to cover rural areas and main transport routes with $5 \mathrm{G}$;

\footnotetext{
${ }^{4}$ The way to avoid entry barriers is relaxing obligations for new entrants. Such a solution was used by the German BNetzA during the last C-band auctions in 2019, which encouraged new entrant to participate in the auction making the auction more competitive.
} 
- during the German auction in the $3.6 \mathrm{GHz}$ band, the coverage and roll-out requirements were extremely exacting compared to this type of auction in other European countries. The regulator's concept, however, was to ensure good coverage through the cooperation agreements between operators. The auction rules encouraged (but did not oblige) operators to cooperate at the service level, e.g. infrastructure sharing and roaming. The key factor promoting cooperation was the fact that the obligations performed with other spectrum holders under cooperation agreements were included as the obligations of each of them;

- one of the $800 \mathrm{MHz}$ licenses in Sweden included an obligation to provide mobile broadband internet in locations where there is currently no access to other forms of broadband internet, so only one operator (who got this license) was obligated to fulfil coverage obligations in unprofitable areas (GSMA, 2016).

Another, less intrusive way to provide coverage is to make publicly available data on the coverage of operators in a given region. Such information allows consumers to make aware decisions about choosing an operator with better services and also encourages others to improve their network as not lose customers. In this way, an appropriate information policy could encourage the improvement of the coverage without government intervention and could often be a sufficient driving force behind the availability of mobile services from auctions as it enhances competition (Webb, 2010). Such a less intrusive approach was adopted at the UK C-band frequency auction in 2018 Ofcom did not implement any coverage obligations during the $3.4 \mathrm{GHz}$ auction, arguing that "market mechanisms should promote spectrum efficiency and be more effective than regulatory interventions in this respect" (Ofcom, 2014, p. 83).

\section{Potential inefficiency during the Polish LTE action}

Auction rules, like other tools of regulatory policy discussed in Section 3, can also be a potential source of inefficiency. An auction that encourages speculative behaviour and/or strategic bidding increases the risk of inefficient outcome and does not maximize social welfare. To ensure efficiency, the auction rules shouldn't favour specific bidders and outcomes, but allow everyone to compete on equal terms. An example of how shortcomings in the auction design may generate the risk of an undesirable outcome will be discussed in the case of the Polish LTE auction.

The Polish regulator (UKE), for the sale of 5 blocks $2 \times 5 \mathrm{MHz}$ in the $800 \mathrm{MHz}$ band and 14 blocks $2 \times 5 \mathrm{MHz}$ in the $2.6 \mathrm{GHz}$ band, applied the rules of the successfully used worldwide simultaneous multiple-round auction (SMRA). This format gives many possibilities of modification, which allows for adapting the auction rules to specific market circumstances. 
The case of the Polish auction shows, however, that even a seemingly small modification auction rules may, in certain circumstances, lead to a lot of distortion and increases the risk of inefficient spectrum allocation.

\subsection{The lack of control over the speed of the auction}

Radio frequencies are a scarce resource of great importance to the economy, therefore it is important to make it available to operators on time. Any delay in spectrum assigning is associated with economic losses related to the inability of using them. In this context, apart from the timely release of spectrum, it is also important that the spectrum allocation process is quick and efficient. For this to happen, the auction rules should allow the regulator to control the pace of the auction and give the ability to bring the auction to the end if necessary ${ }^{5}$. The Polish auction rules did not include sufficient instruments for the regulator to control the pace of the auction. The bid increments were small (ranging from 1 to $5 \%$ ) and only the players decided which one to choose - the auctioneer could not change them. The participants used this favourable auction rule and almost always chose the minimum increment amount of $1 \%$. This led to a very long bidding process, which could not be stopped under the primary auction rules. The Polish auction rules originally included the same ending rule that has been used in SMRAs in many other countries: the auction was supposed to end only after a round that no license received a new bid (Milgrom, 2000). Unfortunately, this rule, combined with the low bid increments and the lack of tools for the regulator to speed up the auction, led to unexpected delays. The bidding lasted 8 months $^{6}$, which resulted in inefficiency related to the delay in the allocation of valuable resources ${ }^{7}$.

\subsection{Changes in ending rules}

The long bidding and high prices of spectrum which significantly exceeding the prices reached in similar auctions in other countries, forced the government, fearing the negative effects of high retail prices, to change the ending rules. These rules assumed that if SMRA did not end within 512 rounds, a final round of sealed bids would be announced. In this round, participants could submit bids without financial limit, but only for blocks they had active bids in the last round of SMRA (i.e. round 512). These rules created an uneven playing field in the sealed final round. They advantaged these players who in round 512 submitted bids for blocks, which had no excess demand, as this guaranteed them to receive the spectrum without having

\footnotetext{
5 The importance of controlling the pace of the auction was convinced by the German regulator BNetzA during the $5 \mathrm{G}$ auction in 2019. This auction lasted 497 rounds and only an increase in the rate increase six times led to its end.

${ }^{6}$ The entire allocation procedure, including the process of consulting the auction rules and explaining the auction documentation took over 2 years.

${ }^{7}$ A detailed analysis of the Polish LTE auction can be found in the article of A. Kuś (see: Kuś, 2020).
} 
to raise the price in the round of sealed bids ${ }^{8}$. Such rules encourage strategic bidding and increase the risk of disturbing the characteristic for SMRA the process of the prices discovering.

Two operators, Orange and $\mathrm{P} 4$, took advantage of the gaps in changed auction rules. In round 512, they made bids for blocks without excess demand, which allowed them to get spectrum without raising the price in the sealed round 513. The prices of three blocks acquired by Orange and P4 (Orange bought 2 blocks, and P4 bought one block) were substantially lower than the prices of the other two blocks for which the operators had to compete in the last round. Thus, the process of market prices discovering taking place during competitive bidding was disturbed and the auction led to the fact that identical licenses were sold at significantly different prices (final prices of blocks in the $800 \mathrm{MHz}$ band varied up to $40 \%$ ).

Another potential source of inefficiency during the Polish $4 \mathrm{G}$ auction was related to the fact that the bids were not binding - the participant could drop out from the auctioned blocks after the auction if, for example, he considered that the amount he was offered was too high. The only cost was the loss of the wadium which was too low to prevent frivolous offers. Although the regulator required the participants to pay deposits it did not constitute sufficient protection against speculative bidding, as deposits were refunded to each participant after the auction (even to those who give up the license). One of the participants - NetNet took advantage of this opportunity and after the final round in which it made the highest bid for a single block in the $800 \mathrm{MHz}$ band, he resigned from the license. It generated a high risk of further delays in spectrum allocation and the risk of spectrum to be unsold.

\subsection{Passive bids}

The next potential source of the Polish auction distortion is the rather unusual way of defining valid bids. The auction regulations assumed to define two types of valid bids: active and passive. The active bid in a given round was the bid submitted in the previous round or the bid that in the previous round was the highest bid for one of the blocks (i.e. was the standing high bid). The introduction of active bids resulted from the characteristic of SMRA activity rule. Each participant to maintain the right to bid had to actively participate in the auction from the beginning. The lack of activity resulted in a partial or total (depending on the undertaken actions) loss of the possibility of bidding at a later stage of the auction. Having an active bid allowed the player to continue bidding. Passive bid (in round $n$ ) was a valid bid submitted in the round preceding the previous round (i.e. round n-2) or in earlier rounds, which wasn't standing high bid and for which the participant did not perform any activity, i.e. did not increase its amount or did not switch it to another block. In other words, if a participant stopped actively bidding on a given block (and did not withdraw an offer by moving it to another block),

\footnotetext{
${ }^{8}$ At that time, the excess demand in the $800 \mathrm{MHz}$ band was two blocks, therefore, the overdemand in the $800 \mathrm{MHz}$ band could be placed on one or two different blocks. In the first case, this would mean that in the final 513 sealed round 3 buyers will compete for one block, while the remaining 4 blocks will be awarded to those participants who placed the highest bids on them in round 512 (the situation what in last rounds there will be no demand for some block was rather unlikely because players could not withdraw their standing high bids).
} 
this offer became the so-called passive bid. The lack of activity and switching to a passive bid on a given block resulted in the loss of eligibility points, and thus the bidding rights at the current level. However, in a situation where the player whose bid in this block was standing high bid withdrawn from the auction or was disqualified, then the next bid in the ranking became standing high bid (even when it was a passive bid). Switching to passive bids, in certain circumstances, gave buyers a chance to stand "in the game" despite the lack of activity in bidding. Thus, such a solution was more advantageous for the player than the withdrawal from the auction, as it gave the opportunity to win a license even when much earlier, at much lower prices, they give up from active bidding.

The motivation for introducing passive bids was most likely to reduce the risk of unsold licenses in the event of a winner's withdrawal. However, such rules, combined with the aforementioned non-binding nature of bids and the lack of safeguards guaranteeing the credibility of bidding created a huge field for manipulation and speculative behaviour. They encouraged the frivolous players, who could make their bids passive in the early stage of the auction, hoping that in the event of winner's resignation or disqualification, it would give a chance to acquire the spectrum at an abnormally low price.

In fact, the pessimistic scenario did not come true. NetNet's bid was not the only bid submitted for this A1 block in the last round of SMRA (see Table 1). After his resignation, this block went to T Mobile (player D), who agreed to accept the abandoned block for the price of PLN 2.022 billion (EUR 478 million) that he offered in the 513 round. Taking into account the existing auction rules, the result could be much more unfavourable. If player D did not decide to take the license at the price he offered, then block A1 would go to the buyer F. The price that he would have to pay for this block would be PLN 357 million (EUR 84 million) and would be almost 6 times lower than the price, which was declared by player B and about 4,5 lower than the average price of the remaining blocks (A2-A5) in the $800 \mathrm{MHz}$ band.

Table 1.

The final phase of bidding on Block A1 during the Polish LTE auction

\begin{tabular}{|c|c|c|c|c|c|c|c|}
\hline \multirow[b]{2}{*}{ Round } & \multirow[b]{2}{*}{$\begin{array}{l}\text { Bidding } \\
\text { format }\end{array}$} & \multicolumn{3}{|c|}{ Active bids } & \multicolumn{3}{|c|}{ Passive bids } \\
\hline & & Bidders & $\begin{array}{l}\text { Ammount } \\
\text { (mln PLN) }\end{array}$ & $\begin{array}{l}\text { Ammount } \\
\text { (mln EUR) }\end{array}$ & Bidders & $\begin{array}{l}\text { Ammount } \\
\text { (mln PLN) }\end{array}$ & $\begin{array}{l}\text { Ammount } \\
\text { (mln EUR) }\end{array}$ \\
\hline 510 & SMRA & B & 1481 & 350 & $\begin{array}{l}\mathrm{F} \\
\mathrm{A}\end{array}$ & $\begin{array}{l}357 \\
353\end{array}$ & $\begin{array}{l}84 \\
83\end{array}$ \\
\hline 511 & SMRA & B & 1481 & 350 & $\begin{array}{l}\mathrm{F} \\
\mathrm{A}\end{array}$ & $\begin{array}{l}357 \\
353\end{array}$ & $\begin{array}{l}84 \\
83\end{array}$ \\
\hline 512 & SMRA & $\begin{array}{l}\text { D } \\
\text { B }\end{array}$ & $\begin{array}{l}1496 \\
1481\end{array}$ & $\begin{array}{l}354 \\
350\end{array}$ & $\begin{array}{l}\mathrm{F} \\
\mathrm{A}\end{array}$ & $\begin{array}{l}357 \\
353\end{array}$ & $\begin{array}{l}84 \\
83\end{array}$ \\
\hline 513 & Sealed bid & $\begin{array}{l}\text { B } \\
\mathrm{D}\end{array}$ & $\begin{array}{ll}\mathbf{2} \mathbf{0 5 3} \\
2022 \\
\end{array}$ & $\begin{array}{l}485 \\
478\end{array}$ & $\begin{array}{l}\mathrm{F} \\
\mathrm{A}\end{array}$ & $\begin{array}{l}357 \\
353 \\
\end{array}$ & $\begin{array}{l}84 \\
83 \\
\end{array}$ \\
\hline
\end{tabular}

Source: Own elaboration based on data from the Office of Electronic Communications (UKE) ${ }^{9}$.

\footnotetext{
${ }^{9}$ The bidding of the last phase of auction described in this part was based on data from the UKE of the detailed course of the auction. Bidders' identities have been encoded in these data and marked with the symbols A-F; therefore, these symbols were used in this paper.
} 
A similar risk would arise if the total surplus of demand in the $800 \mathrm{MHz}$ band (which from round 66 was 2 blocks) was distributed in such a way that in round 512 the buyer's B offer would be the only bid on block A1. Then, according to the changed ending rules, player B would be the only player able to bid in the final round 513. In case of his resignation, player $F$ would receive block A1 at an extremely low price, causing losses in the efficiency.

\section{Conclusions}

The structure of the competition in the selection process and the provision of a sufficient amount of spectrum on time is one of the most important elements of auction designing (Hazlett et al., 2012). According to the report "The Cost of Spectrum Auction Distortions. Review of spectrum auction policies and economic assessment of the impact of inefficient outcomes" delays in spectrum allocation lead to permanent economic losses and do not maximize social welfare. A particularly unfavourable situation occurs when the spectrum, e.g. due to incorrect decisions of regulatory policy, remains unused for a long time. The social losses on this account often exceed the revenues that the government can get from selling the remaining spectrum at an additional auction (GSMA, Frontier Economic, 2015).

Ensuring competition is also extremely important for achieving economic efficiency. An auction, where there are barriers to entry is unlikely to be effective. Regulatory authorities have a number of tools to promote competition both at the auction and on the post-auction market. The goal of these instruments should not, however, be to raise revenue, as such an approach is often contrary to the pro-efficiency goals (Cramton et al., 2011). Extremely high reserve prices or rigorous approach to promoting entry could interfere with the auction process and lead to price distortions, misallocation or even unsold spectrum which harm both competition and consumers. This is confirmed by the empirical examples discussed in this paper.

The case of the Polish 4G auction confirms that gaps in the auction rules may lead to significant delays in frequency allocation and increase the risk of an ineffective auction outcome. Our findings, especially those concerning the control over the speed of the auction and the risk associated with passive bids, should be considered when designing the rules of currently planned in Poland auction on $3.6 \mathrm{GHz}$ band. 


\section{References}

1. Australian spectrum auction failure. Available online http://www.coleago.com/australianspectrum-auction-failure/, 07.10.2020.

2. Cave, M., and Webb, W. (2013). Spectrum Limits and Auction Revenue: the European Experience. Retrieved from https://ecfsapi.fcc.gov/file/7520934210.pdf, 12.10.2020.

3. Cramton, P. (2013a). Spectrum Auction Design. Review of Industrial Organization, Vol. 42, Iss. 2, 161-190.

4. Cramton, P. (2013b). The rationale for spectrum limits and their impact on auction outcomes. Retrieved from http://www.cramton.umd.edu/papers2010-2014/cramtonspectrum-limits-ex-parte.pdf, 2.10.2020.

5. Cramton, P., Kwerel, E., Rosston, G. and Skrzypacz, A. (2011). Using spectrum auctions to enhance competition in wireless services. Journal of Law and Economics, Vol. 54, 197-188.

6. Earle, R. and Sosa, D.W. (2013). Spectrum auctions around the world: An assessment of international experiences with auction restrictions. Analysis Group. Retrieved from https://www.analysisgroup.com/globalassets/insights/publishing/2013_earle_sosa_spectru mauctionsworldwide.pdf, 20.09.2020.

7. Eylert, B. (2002). The Mobile Multimedia Business. Requirements and Solutions. Hoboken: John Wiley \& Sons.

8. GSMA, Coleago Consulting (2014). The Cost of Spectrum Auction Distortions. Review of spectrum auction policies and economic assessment of the impact of inefficient outcomes. Retrieved from https://www.gsma.com/spectrum/wp-content/uploads/2014/11/The-Costof-Spectrum-Auction-Distortions.-GSMA-Coleago-report.-Nov14.pdf, 26.04.2020.

9. GSMA, Frontier Economic (2015). Benefits of network competition and complementary policies to promote mobile broadband coverage. Retrieved from https://www.gsma.com/mobilefordevelopment/wp-content/uploads/2015/02/Benefits-ofnetwork-competition-and-complementary-policies-to-promote-mobile-broadbandcoverage-Report.pdf, 03.07.2020.

10. GSMA (2016). Best practice in mobile spectrum licensing. Retrieved from https://www.gsma.com/spectrum/wp-content/uploads/2016/11/spec_best_practice_ ENG.pdf, 5.09.2020.

11. Hazlett, T., Munoz, R.E., and Avanzini, D.B. (2012). What Really Matters in Spectrum Allocation Design. Northwestern Journal of Technology and Intellectual Property, Vol. 10, Iss. 3, 93-123.

12. ISED, Technical, Policy and Licensing Framework for Spectrum in the $600 \mathrm{MHz}$ Band. Retrieved from http://www.ic.gc.ca/eic/site/smt-gst.nsf/eng/sf11374.html, 15.10.2020. 
13. Kuś, A. (2020). Polish experience from first-ever spectrum auction. Telecommunication Policy, Vol. 44 Iss. 7, 1-11.

14. Marsden, R., Sexton, E., and Siong, A. (2010). Fixed or flexible? A survey of $2.6 \mathrm{GHz}$ spectrum awards. DotEcon Discussion Paper, Iss. 10/01. Retrieved from https://www.dotecon.com/assets/images/dp1001.pdf, 19.02.2020.

15. Maskin, E. (2003). Auctions and Efficiency. In: M. Dewatripont, L. Hansen, and S. Turnovsky (Eds.), Advances in Economic Theory (invited lectures from the 8th World Congress of the Econometric Society) (pp. 1-24). Cambridge: Cambridge University Press.

16. Masse, M., Beaudry, P. (2014). The State of Competition in Canada's Telecommunications Industry. Montreal: Montreal Economic Institute.

17. McMillan, J. (1994). Selling Spectrum Rights. Journal of Economic Perspectives, Vol. 8, Iss. 3, 145-162.

18. Milgrom, P. (2000). Putting auction theory to work: The simultaneous ascending auction. Journal of Political Economy, Vol. 108, Iss. 21, 245-272.

19. Mochon, A., Saez, Y. (2017). A Review of Radio Spectrum Combinatorial Clock Auctions. Telecommunications Policy, Vol. 41, Iss. 5-6, 303-324.

20. OECD (2001). Spectrum allocation: Auctions and comparative selection procedures. Economic Arguments. Report Working Party on Telecommunication and Information Services Policies DSTI/ICCP/TISP(2000)12/FINAL. Retrieved from https://www.oecd.org/sti/broadband/27125982.pdf, 18.12.2019.

21. Ofcom (2014). Public Sector Spectrum Release (PSSR) - Award of the $2.3 \mathrm{GHz}$ and $3.4 \mathrm{GHz}$ bands - Consultation document. Retrieved from https://www.ofcom.org.uk/ __data/assets/pdf_file/0025/78055/Public_Sector_Spectrum_Release_2-3_and_34_ghz_award.pdf, 17.07.2020.

22. Ofcom (2017). Award of the 2.3 and $3.4 \mathrm{GHz}$ spectrum band. Competition issues and Auction Regulations. Retrieved from https://www.ofcom.org.uk/_data/assets/pdf_file/ 0022/103819/Statement-Award-of-the-2.3-and-3.4-GHz-spectrum-bands-Competitionissues-and-auction-regulations.pdf, 17.07.2020.

23. Ostrowsky, M. (2019). Comments on the Outcomes and Design Issues in the 2019 Canadian Auction of Spectrum Licenses in the $600 \mathrm{MHz}$ Band. Retrieved from https://www.ic.gc.ca/eic/site/smt-gst.nsf/vwapj/SLPB-002-19-TELUS-Attachment3.pdf/ \$FILE/SLPB-002-19-TELUS-Attachment3.pdf, 18.10.2020.

24. Rosston, G.L., Steinberg, J.S. (1997). Using Market-Based Spectrum Policy to Promote the Public Interest. Federal Communications Law Journal, Vol. 50, Iss. 1, 87-116.

25. Van Damme, E. (2002). The European UMTS-Auctions. European Economic Review, Vol. 46, 846-869. 
26. Webb, W. (2010). Being Mobile: Future Wireless Technologies and Applications. Cambridge: Cambridge University.

27. Zehle, S. (2019). Sustainable spectrum pricing. Fostering the deployment of $5 G$ through appropriate spectrum pricing. Retrieved from http://www.coleago.com/wpcontent/uploads/2019/07/Sustainable-Spectrum-Pricing-Coleago-June-2019-1.pdf, 18.09.2020. 